\title{
Statyba
}

\section{AKYTOJO BETONO GARSO ABSORBCIJOS TYRIMAI}

\author{
A. Laukaitis , V. Lasauskas , A. Laukaitis \& V. Lasauskas
}

To cite this article: A. Laukaitis , V. Lasauskas , A. Laukaitis \& V. Lasauskas (1996) AKYTOJO BETONO GARSO ABSORBCIJOS TYRIMAI, Statyba, 2:8, 67-72, DOI: 10.1080/13921525.1996.10590174

To link to this article: https://doi.org/10.1080/13921525.1996.10590174

曲 Published online: 01 Nov 2012.

Submit your article to this journal $\pi$

山 Article views: 94

4 Citing articles: 1 View citing articles 준 


\section{AKYTOJO BETONO GARSO ABSORBCIJOS TYRIMAI}

\section{A. Laukaitis, V. Lasauskas}

\section{Ivadas}

Viena iš teigiamy akytojo betono savybiu yra galëjimas absorbuoti garso bangas. Užsienio šalił literatūroje nedaug duomenų apie akytojo betono garso absorbciją. Dažniausiai buvo nustatomas garso bangu absorbcijos koeficientas Itong, Hebel, Siporeks firmų didesnio tankio $\left(500-600 \mathrm{~kg} / \mathrm{m}^{3}\right)$ gaminių, kurie naudojami kaip konstrukcinè medžiaga. Be specialaus apdorojimo tokiu gaminiy garso absorbcijos koeficientas yra labai nedidelis [1, 2].

Termoizoliacijos instituto mokslininkai yra ištyrę $300-500 \mathrm{~kg} / \mathrm{m}^{3}$ tankio akytojo betono garso bang 4 absorbcijos priklausomybę nuo gaminių tankio, struktūros, storio bei gaminiu paviršiaus mechaninio apdorojimo [3-7]. Šiame straipsnyje pateikiami akytojo betono garso absorbcijos tyrimo rezultatai, apimantys anksčiau skelbtus bei naujus duomenis.

\section{Tyrimų metodika}

Normalinis garso absorbcijos koeficientas buvo nustatytas interferometru naudojant firmos "Briul ir Kjer" aparatūrą [8]. Pavyzdžių reverberacinis garso absorbcijos koeficientas $\alpha$ buvo nustatytas Termoizoliacijos instituto reverberacineje kameroje, naudojant $12 \mathrm{~m}^{2}$ bandomąsias konstrukcijas, išdėstytas ant kameros grindų [9]. Akytojo betono banginiai para- metrai (santykinė banginè varža ir plitimo konstanta), apibūdinantys garso bangų elgseną porètose terpèse, buvo nustatyti akustiniu interferometru [10].

\section{Rezultatai ir ju aptarimas}

Nustatyti $350 \mathrm{~kg} / \mathrm{m}^{3}$ tankio akytojo betono banginiai parametrai [11] pateikti 1 lentelèje. Čia: $W$ santykinè banginè varža; $a$ - realioji santykinès banginès varžos komponenté; $b$ - menamoji santykinès banginès varžos komponentė; $\alpha$ - realioji plitimo konstantos komponenté; $\beta$ - menamoji plitimo konstantos komponentè. Iš 1 lentelès matome, kad didèjant dažniui santykinès banginès varžos komponenčiu absoliučios vertès mažèja, o plitimo konstantos komponentès - dideja.

Akytojo betono santykinès banginès varžos modulis yra didesnis už oro banginę varžą $(W=1)$, todèl šią akytą medžiagą galima priskirti medžiagai su didele varža oro srautui, t.y. medžiagoms su patenkinama garso absorbcija.

Nustačius banginių parametrų reikšmes, ịvairaus storio akytojo betono bandiniu normalinius garso absorbcijos koeficientus galima apskaičiuoti pagal formules $[12,13]$ :

$$
\alpha_{0}=\frac{4 x}{(x+1)^{2}+y^{2}},
$$

1 lentelè. Akytojo betono banginiai parametrai

Table 1. Porous concrete wave parameters

\begin{tabular}{|c|c|c|c|c|}
\hline \multirow{2}{*}{ Dažnis, Hz } & \multicolumn{2}{|c|}{ Santykinè banginè varža $W$} & \multicolumn{2}{c|}{ Plitimo konstanta $\gamma$} \\
\cline { 2 - 5 } & $a$ & $b$ & $\alpha, \mathrm{m}^{-1}$ & $\beta, \mathrm{m}^{-1}$ \\
\hline 125 & 17.1 & -11.0 & 36.6 & 36.1 \\
\hline 250 & 13.6 & -4.9 & 43.1 & 44.9 \\
\hline 500 & 11.4 & -3.3 & 52.8 & 73.1 \\
\hline 1000 & 9.7 & -1.9 & 71.9 & 101.0 \\
\hline 2000 & 8.5 & -0.5 & 102.8 & 104.8 \\
\hline
\end{tabular}


čia:

$$
\begin{gathered}
x=\frac{a \cdot \operatorname{sh}(2 \alpha l)+b \cdot \sin (2 \beta l)}{\operatorname{ch}(2 \alpha l)-\cos (2 \beta l)}, \\
y=\frac{b \cdot \operatorname{sh}(2 \alpha l)-a \cdot \sin (2 \beta l)}{\operatorname{ch}(2 \alpha l)-\cos (2 \beta l)} .
\end{gathered}
$$

Čia: $\alpha_{0}$ - normalinis garso absorbcijos koeficientas; $l$ bandinio storis, $\mathrm{m} ; \boldsymbol{x}$ - bandinio impedanso realioji komponenté; $y$ - bandinio impedanso menamoji komponentè.

Normalinio koeficiento priklausomybè nuo bandinio storio pateikta 1 paveiksle. Jame matome, kad $35 \mathrm{~mm}$ ir storesniy bandiniu normalinis garso absorbcijos koeficientas nekinta. Tai reiškia, kad tokio storio bandinių impedansas sutampa su medžiagos bangine varža, t.y. gaminiai tiriamame dažniụ diapazone atliks begalinès terpès vaidmenị. Tokiais atvejais garsą absorbuojančiy gaminiu akustinis efektyvumas nesikeis net konstrukcijose su oro tarpu (kabamosios lubos).

Mažèjant akytojo betono tankiui, kaip ir reikèjo tikètis, garso absorbcijos koeficientas didèja (2 pav.). 2 paveiksle vidutinio normalinio garso absorbcijos koeficiento (aritmetinis vidurkis reikšmių esant nurodytiems dažniams) priklausomybè nuo bandinio tankio yra tiesinè linija ( 3 pav.).

2 paveikslo vidutiniu reikšmiu priklausomybès aprašomos tiesine lygtimi ( 3 pav.).

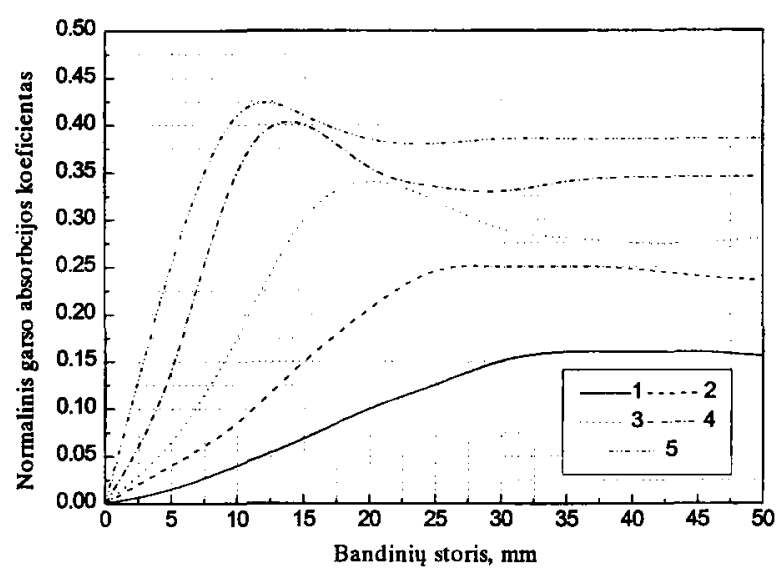

1 pav. Akytojo betono normalinio garso absorbcijos koeficiento priklausomybè nuo bandinių storio, kai dažnis Hz: 1 - 125; 2 - 250; 3 - 500; 4 - 1000; 5 - 2000

Fig. 1. Porous concrete normal sound absorption coefficient dependency on sample thickness at frequencies, Hz: 1 - 125; 2 - 250; 3 - 500; 4 - 1000; 5 - 2000
Tačiau garso absorbcijos koeficientas priklauso ne tik nuo akytojo betono tankio, bet ir nuo jo rūšies. Tokio pat tankio akytojo betono garso absorbcijos koeficiento priklausomybè nuo akytojo betono rūšies parodyta 4 paveiksle.

Nevienodas tokio pat tankio akytojo betono garso absorbcijos koeficiento reikšmes galima paaiškinti skirtinga ịvairiu rūšị akytojo betono gaminių struktūra, t.y. pasikeičia poru matmenys, jų kiekis bei pasiskirstymas (5 pav., 2 lentelè).

Akustinių plokščị gamyba iš akytojo betono parodè, $\mathrm{kad} 280-350 \mathrm{~kg} / \mathrm{m}^{3}$ tankio akytojo betono gaminiai nèra pakankamai stiprūs. Todèl buvo nuspręsta padidinti akytojo betono, naudojamo akustiniams gaminiams, tanki iki $460 \mathrm{~kg} / \mathrm{m}^{3}$. Tačiau 2 paveiksle pateikti tyrimo rezultatai rodo, kad tokiu gaminiu garso absorbcijos koeficientas gerokai sumažeja. Siekiant padidinti garso absorbcijos koeficientą, plokštėse buvo išpjauti specialūs skirtingy formu rezonatoriai ("Helmholco" rezonatoriai). Išpjovų formos itaka garso absorbcijai parodyta 6 paveiksle (išpjovų žingsnis $22 \mathrm{~mm}$ ).

Matavimai reverberacinėje kameroje parodè, kad išpjovus akytajame betone sudètingesnès formos rezonatorius arba padidinus jų tūri, garso absorbcijos koeficientas dideja. Tačiau pagaminti plokštes su sudètingos formos rezonatoriais yra labai sunku. Daug paprasčiau išpjauti taisyklingos cilindrinès formos rezonatorius. Plokščiu su taisyklingais sferos formos rezonatoriais reverberacinis garso absorbcijos koeficientas pateiktas 7 paveiksle.

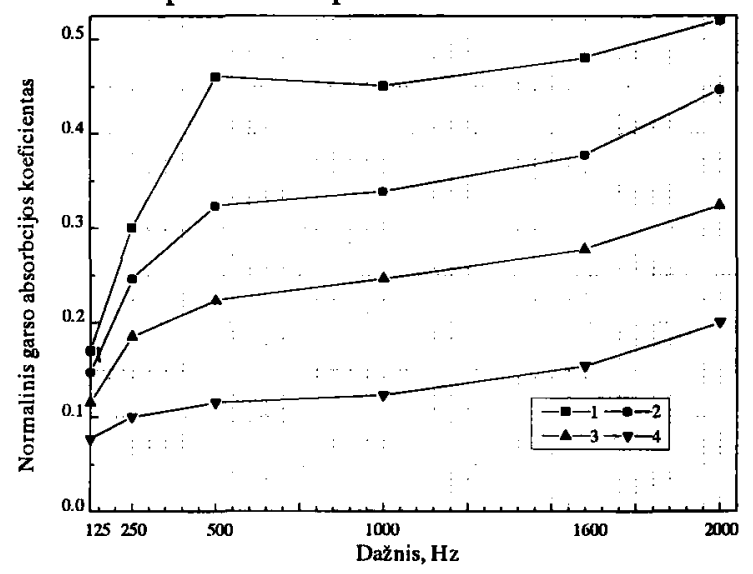

2 pav. Normalinio garso absorbcijos koeficiento priklausomybè nuo dažnio, kai dujų silikatbetonio tankis, $\mathrm{kg} / \mathrm{m}^{3}: 1$ - 280; 2 - 380; 3 - 470; 4 - 670

Fig. 2. Normal sound absorption coefficient dependency on frequency at cellular silicate density, $\mathrm{kg} / \mathrm{m}^{3}: 1-280 ; 2$ - 380; 3 - 470; 4 - 670 


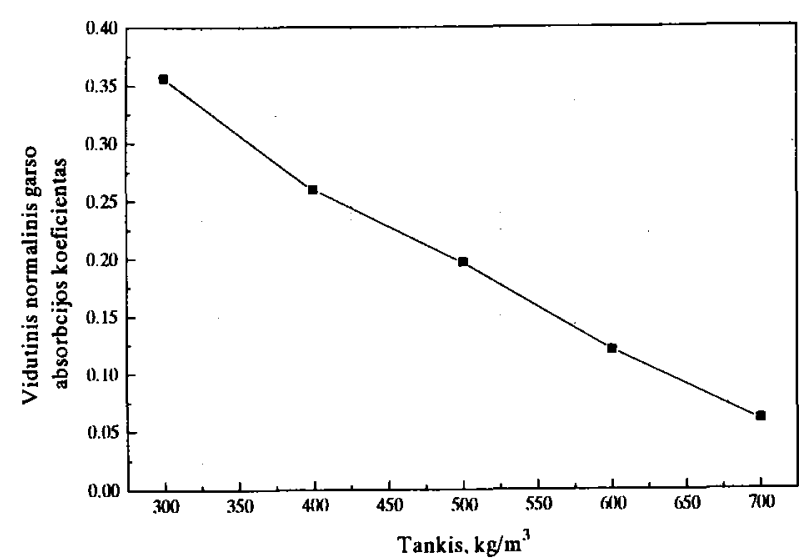

3 pav. Vidutinio garso absorbcijos koeficiento priklausomybè nuo akytojo betono tankio

Fig. 3. Average sound absorption coefficient dependency on porous concrete density

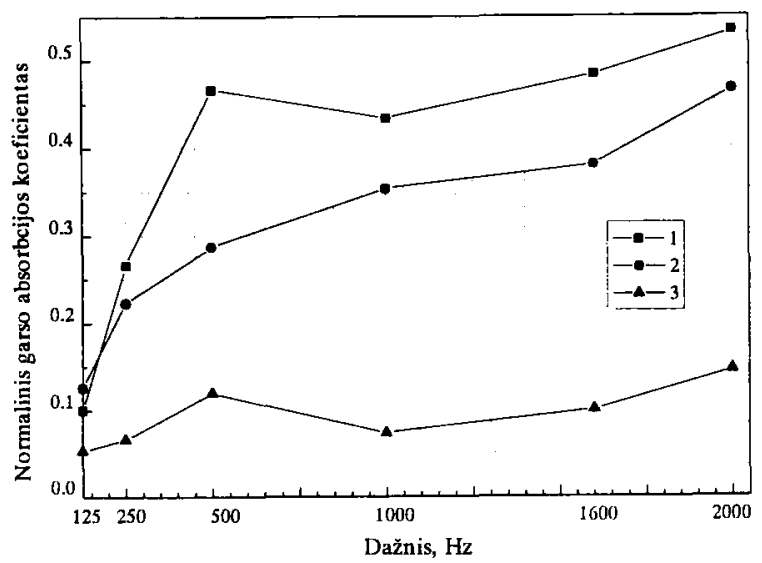

4 pav. Akytojo betono garso absorbcijos koeficiento priklausomybè nuo dažnio: 1 - dujų silikatbetonis; 2 - putųdujų silikatbetonis; 3 - putbetonis

Fig. 4. Porous concrete sound absorption coefficient dependency on frequency: 1 - cellular silicate concrete; - foam-gas cellular concrete; 3 - foam concrete

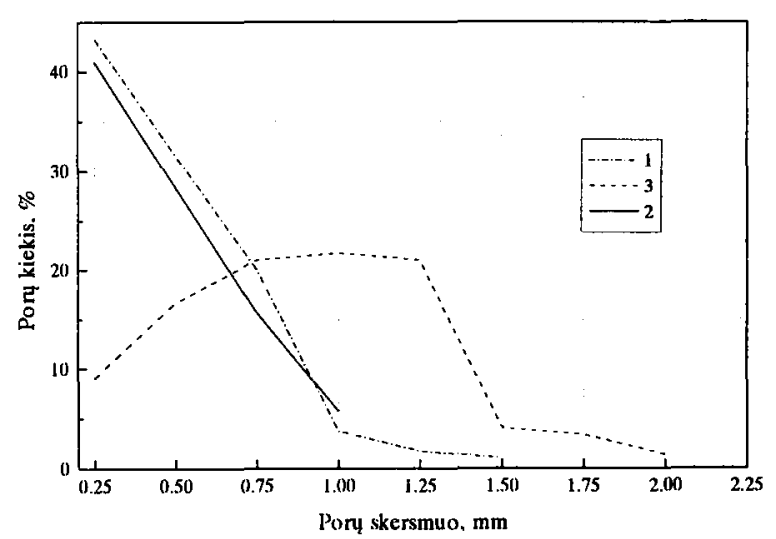

5 pav. Poru pasiskirstymas akytajame betone: 1 - putbetonis; 2 - putu-duju silikatbetonis; 3 - dujų silikatbetonis

Fig. 5. Distribution of pores in porous concrete: 1 - foam concrete; 2 - foam-gas silicate concrete; 3 - gas silicate concrete

Dèl išpjovų akytojo betono plokštėse mažeja plokščiu paviršiaus akustinè varža, todèl dideja garso absorbcijos koeficientai ( 7 pav., 2 ir 3 kreivès).

Daugelio tirtų konstrukciju garso absorbcijos koeficientai yra didesni už 1 . Tai aiškinama sudètinga garso bangų elgsena panašaus tipo konstrukcijose (garso difrakcijos reiškiniai plokščių kraštuose) [14].

Akytojo betono plokštes su abiejose plokšči pusèse išpjautais minèty formų rezonatoriais galima naudoti erdvinèse konstrukcijose mažinant triukšmą gamybinèse patalpose. Šiuo atveju konstrukcijos garso absorbcijos koeficientas priklauso nuo plokščụ išdèstymo erdvejje būdo. Ištirtos trijų tipu erdvinès konstrukcijos (8 pav., 3 lentelè).

2 lentelè. Akytojo betono porų struktūra

Table 2. Porous concrete pore structure

\begin{tabular}{|c|c|c|c|c|}
\hline Rodiklio pavadinimas & Mato vienetas & $\begin{array}{c}\text { Duju } \\
\text { silikatbetonis }\end{array}$ & $\begin{array}{l}\text { Putų-duju } \\
\text { silikatbetonis }\end{array}$ & Putbetonis \\
\hline \multirow[t]{2}{*}{ Porų kiekis: } & $\%$ & 74.6 & 72.0 & 75.5 \\
\hline & $\%$ & 14.9 & 17.5 & 14.0 \\
\hline \multirow{2}{*}{$\begin{array}{r}\text { Porų kiekis plokštumoje: makroporos } \\
\text { mikroporos }\end{array}$} & vnt. $/ \mathrm{m}^{3}$ & 69 & 200 & 219 \\
\hline & $\mathrm{vnt} . / \mathrm{m}^{3}$ & 370 & 437 & 349 \\
\hline \multirow{2}{*}{$\begin{array}{c}\text { Pory kiekis tūrio vienete: makroporos } \\
\text { mikroporos }\end{array}$} & $\mathrm{vnt} . / \mathrm{m}^{3}$ & 375 & 3106 & 3525 \\
\hline & $\mathrm{vnt} . / \mathrm{m}^{3}$ & 10560 & 12404 & 9920 \\
\hline Vidutinis porų skersmuo plokštumoje & mm & 0.587 & 0.338 & 0.335 \\
\hline Vidutinis poru skersmuo tūryje & $\mathbf{m m}$ & 0.624 & 0.382 & 0.372 \\
\hline Vidutinis kvadratinis nuokrypis & mm & 0.297 & 0.149 & 0.137 \\
\hline Vidutinis sieneliu storis tarp pory & $\mathrm{mm}$ & 0.373 & 0.245 & 0.207 \\
\hline Poru paviršiaus plotas tūrio vienete & $\mathrm{mm}^{2} / \mathrm{cm}^{3}$ & 680 & 1142 & 1180 \\
\hline
\end{tabular}




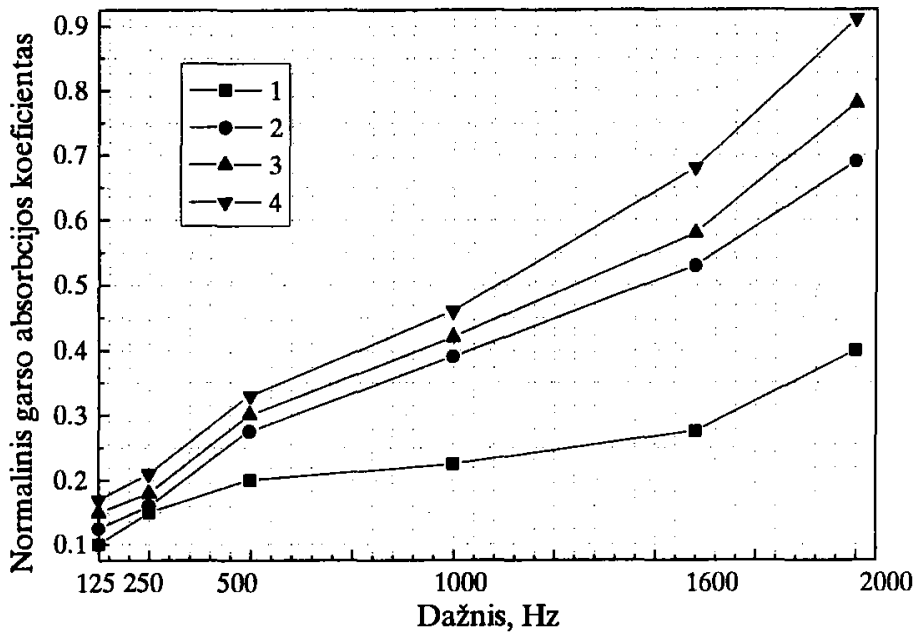

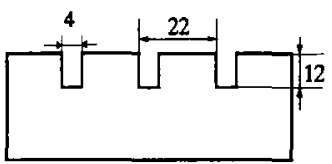

1

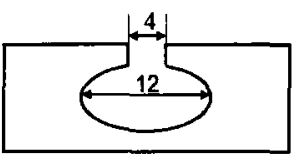

3

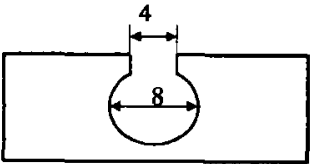

2

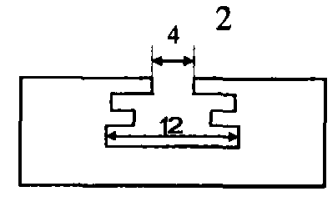

4

6 pav. Rezonatorių formos įtaka akytojo betono garso absorbcijos koeficientui

Fig. 6. Porous concrete resonator form influence on sound absorption coefficient
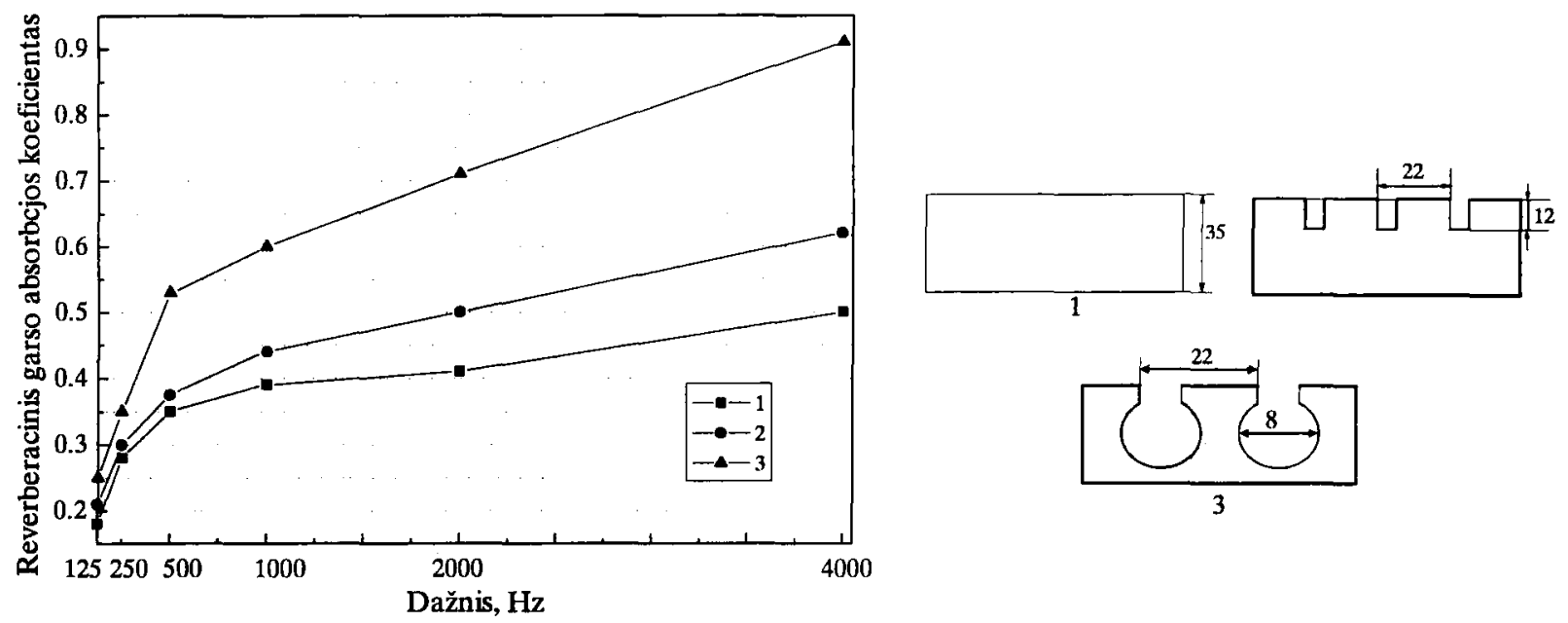

7 pav. Išpjovos formos įtaka $460 \mathrm{~kg} / \mathrm{m}^{3}$ tankio akytojo betono plokščiu garso absorbcijai: 1 - plokštès be išpjovu; 2 stačiakampes išpjovos ("Styga"); 3 - "Helmholco" tipo rezonatoriai

Fig. 7. The influence of cuts on $460 \mathrm{~kg} / \mathrm{m}^{3}$ density porous concrete slab sound absorption: 1 - slabs without cuts; 2 - with rectangular cuts; 3 - with cavity-type resonator (Helmholtz)

3 lentelè. Plokščį su rezonatoriais išdèstymo erdveje būdai

Table 3. Slab with resonators lay-out methods

\begin{tabular}{|c|c|c|c|}
\hline Kreivès nr. & Išdèstymo & \multicolumn{2}{|c|}{ Atstumas tarp eilių, $\mathrm{m}$} \\
\cline { 3 - 4 } & būdas & $L$ & $l$ \\
\hline 1 & I & 0 & 0.9 \\
\hline 2 & I & 0 & 0.45 \\
\hline 3 & I & 0.25 & 1.0 \\
\hline 4 & I & 0.25 & 0.5 \\
\hline 5 & II & - & 0.9 \\
\hline 6 & II & - & 0.45 \\
\hline 7 & III & - & 0.65 \\
\hline 8 & III & - & 0.55 \\
\hline 9 & III & - & 0.45 \\
\hline 10 & III & - & 0.25 \\
\hline
\end{tabular}

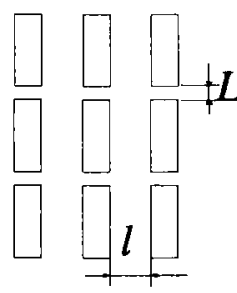

I būdas

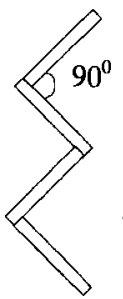

II būdas

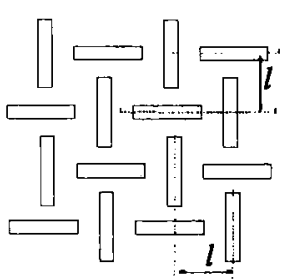

III būdas 


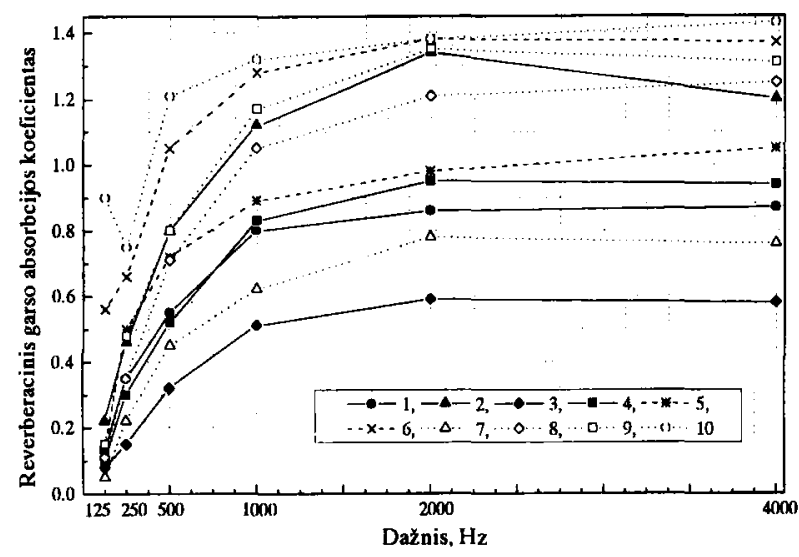

8 pav. Reverberacinio garso absorbcijos koeficiento priklausomybè nuo dažnio esant ịvairiems plokščiu su rezonatoriais išdestymo erdveje būdams (3 lentelè)

Fig. 8. Reverberation sound absorption coefficient dependency on frequency for various slabs with resonators lay-outs (Table 3)

Pačios efektyviausios iš visu tirtų konstrukciju tos, kur akytojo betono plokštès su abipuse perforacija pakabinamos suglaustos (8 pav., 6 ir 10 kreivès). Jos efektyvios visame tirtame $125 \div 4000 \mathrm{~Hz}$ dažnių diapazone. Didinant atstumą tarp plokščių, reverberacinis garso absorbcijos koeficientas mažeja visu tipy konstrukcijose (8 pav., 1 ir 2, 5 ir 6, $7-10$ kreivès). Taigi parenkant akytojo betono plokščiy išdèstymo erdvèje būdą, galima keisti konstrukcijos garso absorbcijos koeficientą.

\section{Išvados}

1. Akytojo betono garso absorbcija priklauso nuo gaminio tankio, kuriam mažejjant garso absorbcijos koeficientas didèja.

2. $300-450 \mathrm{~kg} / \mathrm{m}^{3}$ tankio akytojo betono garso absorbcijos koeficientas priklauso nuo akytojo betono rūšies, t.y. nuo jo pory struktūros. Duju silikatbetonio struktūroje vyrauja didesnio skersmens susisiekiančios poros, todèl jo garso absorbcijos koeficientas yra didesnis nei putbetonio, kurio struktūrą sudaro uždaros poros.

3. Akytojo betono garso absorbcijos koeficientas priklauso nuo bandinių storio. Nustatyta, kad padidinus bandinių storị per $35 \mathrm{~mm}$, normalinis garso absorbcijos koeficientas nekinta.

4. Specialios ivvairiu formy išpjovos akytojo betono plokštèse padidina jo garso absorbcijos koeficientą iki 2 kartų. Geriausiai garsą sugeria plokštės su išpjautais specialiais Helmholco rezonatoriais.

5. Iš $300-450 \mathrm{~kg} / \mathrm{m}^{3}$ tankio akytojo betono plokščị su abiejose ju pusėse išpjautais rezonatoriais erdviniu konstrukcijy garso absorbcijos koeficientas priklauso nuo plokščị išdestymo būdo konstrukcijoje. Pakabinus jas $0.25 \div 0.65 \mathrm{~m}$ atstumu tarp plokščiu centrų, reverberacinis garso absorbcijos koeficientas padidejja iki 90\%, palyginus su tradicinès plokščios konstrukcijos garso absorbcijos koeficientu.

\section{Literatüra}

1. G.Bave, N.J.Bright, F.N.Leitch, W.Rottan, G.Svanholm, V.P.Trambovetsky, J.W.Weber. Автоклавный ячеистый бетон (Перевод с англ.). М.: Стройиздат, $1981.85 \mathrm{c}$.

2. Hebel. Technical Handbook. Edition 5. Updated may 1992, p. 5-9.

3. А.А.Лаукайтис. Исследование технологии изготовления и свойств звукопоглощающих плит "силакпор" на цементно-песчаном и известковоцементно-песчаном вяжущем: Автореферат дис. канд. техн. наук. Каунас, 1975. $22 \mathrm{c}$.

4. А.А.Лаукайтис, А.Е.Биховскис, А.А.Стонкус. Влияние некоторых фактурных рисунксв и крептения плит "силакпор" на их звукопоглощение // Сборник трудов ВНИИтеплоизоляция. Вып. 10. Вильнюс, 1977, с. 84-88.

5. М.-Г.С.Казлаускене. Разработка технологии производства и изучение свойств звукопоглощающих плит "силакпор" из известково-песчаной смеси: Автореферат дис. ... канд. техн. наук. М., 1978. 22 с.

6. А.А.Лаукайтис, А.Е.Биховскис. Исследование технологических параметров производства и некоторых свойств модифицированных звукопоглощающих плит "силакпор" // Сборник трудов ВНИИтеплоизоляция. Технология теплоизоляционных и акустических изделий из ячеистого бетона. Вильнюс, 1983, с. 3-8.

7. Г.А.Тарвидас, В.И.Ласаускас, А.А.Лаукайтис. Исследование технологических параметров изготовления и свойств объемных звукопоглотителей "порасил" // Сборник трудов ВНИИтеплоизоляция. Технология теплоизоляционньх и акустических изделий на основе местных вяжуших. Вильнюс, 1986 , c. $77-81$.

8. ГОСТ 16297-80. Материалы звукоизолирующие и звукопоглощающие. Методы испытаний. С. 5-9.

9. СТ СЭВ 1929-79. Шум. Метод измерения звукопоглощения в реверберационной камере. С. 1-7.

10. Руководство по измерению и расчету акустических характеристик звукопоглощающих материалов // НИИ строит. физики. М.: Стройиздат, 1979, с. 4-6.

11. В.И.Ласаускас, А.А.Стонкус. Исследование акустических свойств газобетона на известково-песчаном вяжущем // Сборник трудов ВНИИтеплоизоляция. Технология теплоизоляционных и акустических изделий на основе местных вяжущих. Вильнюс, 1986, с. 72-76. 
12. Л.Ф.Лепендин. Акустика: Учебное пособие для втузов. М.: Высш.шк., 1978. 448 с.

13. Авиационная акустика / Под. ред. канд. техн. наук А.Г.Мунина и В.Е.Квитки. М.: Машиностроение, 1973. $447 \mathrm{c}$.

14. Г.Л.Осипов, Е.Я.Юдин и др. Снижение шума в зданиях и жилых районах / Под ред. Г.Л.Осипова, Е.Я.Юдина. М.: Стройиздат, 1987. 558 с.

\section{İteikta 19960610}

\section{POROUS CONCRETE SOUND ABSORPTION INVESTIGATION}

\section{A. Laukaitis, V. Lasauskas}

\section{S u m m a r y}

Low-density porous concrete can be used as a sound absorbing material. This paper generalizes porous concrete sound absorption investigations.

Porous concrete relative wave resistance modulus is longer than air wave resistance $W=1$ and that is why this material can be ascribed to materials with a high resistance to air flows, i.e. materials with a satisfactory sound absorption.

Various thickness porous concrete sample sound absorption coefficients can be calculated according to equations (1), (2), (3), when wave parameter values are determinated (Table 1). Normal sound absorption coefficient measurement results (Fig. 1) show that for $35 \mathrm{~mm}$ and thicker samples the coefficient does not vary. It means that the samples apparent resistance (impleance) coincides with the materials wave resistance.

The sound absorption coefficient increases (Fig. 2) with a decrease in porous concrete density. The asymmetric average dependency is expressed by a rectilinear curve (Fig. 3). The sound absorption coefficient depends not only on porous concrete density, but also on its nature (Fig. 4). The different sound absorption coefficient values for uniform density porous concrete can be explained by the various structure of porous concrete products, i.e. a change in pore dimensions, their amount and distribution (Fig. 5, Table 2).

The production of acoustical slabs has shown that 280$350 \mathrm{~kg} / \mathrm{m}^{3}$ density porous concrete products are not sufficiently strong. It was therefore decided to increase their density to $460 \mathrm{~kg} / \mathrm{m}^{3}$, with the purpose of increasing the sound absorption coefficient by using various special form resonators (cavity-type accelerators).

The influence of the cuts on sound absorption is given in Fig. 6 (cut step is $22 \mathrm{~mm}$ ). Measurements in a reverberation chamber have shown that the sound absorption coefficient value in porous concrete slabs with deeper or complex cuts increases, but it is harder to produce slabs with complex form cuts.

It is easier to make a simple form resonator. Reverberated sound absorption for regular form resonators is given in Fig. 7. Porous concrete slab surface acoustical resistance decreases due to cuts and that is why there is an increase in sound absorption coefficients (Fig. 7, 2 and 3 curves).Porous concrete slabs with resonator cuts on both sides can be used in spacious constructions, for noise absorption in industrial premises. In this case, the construction sound absorption coefficient depends on the lay-out of these slabs.

Three types of special lay-outs were investigated (Fig. 8, Table 3). Most of the investigated constructions have revertible sound absorption coefficients higher than 1 . This is explained by sound diffraction phenomena on the slab edges.

The most effective of all the investigated constructions are those where porous concrete slabs with two-sided perforations are hung jointly (Fig. 8, curves 6 and 10). They are effective in the entire distance between the slabs. The reverberation absorption coefficient decreases for all types of constructions (Fig. 8, curves 1 and 2, 5 and 6, 7-10). The special construction sound absorption coefficient can be changed by selecting porous concrete slab lay-out.

Antanas LAUKAITIS. Doctor of technical sciences. Director of Institute Termoizoliacija, 28 Linkmeny St, 2600 Vilnius, Lithuania.

A graduate of Kaunas Polytechnical Institute (1967), industrial engineer. Doctor's degree in 1975 (the thesis on acoustical products of porous concrete). In 1992 A.Laukaitis worked as a researcher at Swedish universities. Author of 76 papers, 16 inventions and 4 patents. Research interests: thermal insulating and acoustical products made of porous concrete, their technology; heat insulating and acoustical materials.

Vytautas LASAUSKAS. Junior research fellow at the Institute "Termoizoliacija", 28 Linkmeny St, 2600 Vilnius, Lithuania. Research interests: building materials, acoustical properties of constructions. 